\title{
Induction of Labor Using Misoprostol With or Without Mifepristone in Intrauterine Death
}

\author{
Ajay Agrawal, ${ }^{1}$ Pritha Basnet, ${ }^{1}$ Achala Thakur, ${ }^{1}$ Pappu Rizal, ${ }^{1}$ Rubina Rai \\ 'B.P. Koirala Institute of Health Sciences, Dharan, Nepal.
}

\section{ABSTRACT}

Introduction: Rapid expulsion of fetus in intrauterine fetal death is usually requested without any medical grounds for it. So an efficient, safe method for induction of labor is required. The objective of this study is to determine if pre-treatment with mifepristone followed by induction of labor with misoprostol in late intrauterine fetal death is more efficacious.

Methods: We conducted a randomized controlled trial in 100 patients in B.P.Koirala Institute of Health Sciences, Nepal from June 2011 to May 2013. Group A women received single oral dose of $200 \mathrm{mg}$ mifepristone, followed by induction with vaginal misoprostol after 24 hours. Group B women were induced only with vaginal misoprostol. In each group, five doses of misoprostol was used four hourly. If first cycle was unsuccessful, after break of 12 hour, second course of misoprostol was started. The primary outcome was a measure of induction to delivery time and vaginal delivery within 24 hours. Secondary outcome was to measure need of oxytocin and complications.

Results: Maternal age, parity and period of gestation were comparable between groups. Number of misoprostol dose needed in group A was significantly less than group B. Mann Whitney U test showed, women in group A had significantly earlier onset of labor, however total induction to delivery interval was not significant. In group A, 85.7\% delivered within 24 hours of first dose of misoprostol while in group B 70\% delivered within 24 hours ( $p=0.07)$. More women in Group B required oxytocin.

Conclusions: Pretreatment with mifepristone before induction of labor following late intrauterine fetal death is an effective and safe regimen. It appears to shorten the duration of induction to onset of labor.

Keywords: induction of labor; intrauterine fetal death; mifepristone; misoprostol.

\section{INTRODUCTION}

Management of intra uterine fetal death (IUFD) poses a dilemma and is often reliant on consultant experience and contradicting literature. Labor following IUFD often needs to be induced by medical means. Inducing labor in a pregnant woman with an unripe cervix is associated with failed induction of labor and a higher risk of caesarean delivery. Within past two decades, prostaglandins have provided an alternative method for induction of labor (IOL) in women with IUFD. ${ }^{1}$

Correspondence: Dr. Ajay Agrawal, Department of Obs/Gyn, B.P. Koirala Institute of Health Sciences, Dharan, Nepal. Email: drajayagrawal@yahoo.com, Phone: +977-9852049451. 
Prostaglandin analogs, such as misoprostol, have been extensively studied and proven to be safe and effective in the induction of abortion in second trimester of pregnancy. $^{2}$

Antiprogestins (including mifepristone) have been developed to antagonize the action of progesterone, and have recognized role in medical termination of early or mid trimester pregnancy. ${ }^{3,4}$ However, there is insufficient information available from clinical trials to support their use to induce labor in later gestation. Several observational and non-comparative studies have suggested that combined use of mifepristone and misoprostol can shorten the induction-to-delivery time by 7-10 hours in IUFD. ${ }^{5,6,7}$ Recently, RCOG provided 'Grade D recommendation' for combined use of mifepristone and a prostaglandin preparation as the first-line intervention for induction of labor in IUFD. ${ }^{8}$

There is lack of randomized study regarding combined use of mifepristone-misoprostol and misoprostol only in the management of IUFD. The RCOG guideline also highlighted the need for good quality study to determine safe and effective methods for induction of labor and the optimal dose of misoprostol for according to gestational age. ${ }^{8}$

The aim of this study was to compare the use of a combination of mifepristone and misoprostol versus misoprostol-only in induction of labor in cases of IUFD.

\section{METHODS}

This prospective randomized study was carried out in the department of obstetrics and gynecology, B.P.Koirala Institute of Health Sciences, Nepal from June 2011 to May 2013 after ethical clearance from Institutional ethical review board.

The criteria for IUFD were gestational age equal or greater than 20 weeks of gestation or $500 \mathrm{~g}$. Gestational age was based on reliable menstrual history and/or confirmation by ultrasonographic measurements performed in early pregnancy. Women in labor on arrival at hospital, previously scarred uterus and with any obstetrical indication for immediate delivery were excluded. All eligible women were invited to give informed consent and were consecutively enrolled.

A detailed history, physical and obstetric examination was done. The diagnosis of intrauterine death was confirmed on ultrasound. Baseline investigation was done according to hospital protocol. All eligible women were randomly assigned to either induction with misoprostol, 24 hours after oral mifepristone, or induction directly with misoprostol. Opaque envelopes were consecutively numbered by means of a computer generated randomization table. As each patient gave consent for the study, the next envelope was opened to assign the patients to either of the two groups.

Group A: Mifepristone followed by induction with misoprostol

Group B: Induction with misoprostol

Group A women were given a single dose of $200 \mathrm{mg}$ oral mifepristone following which, after 24-hour interval, they were induced with tab misoprostol administered vaginally into posterior fornix. Group B women were induced with tab misoprostol administered vaginally into posterior fornix.

In both groups, after the first dose, further misoprostol was inserted vaginally four hourly till they went into labor or deliver the fetus whichever occurred early. Dose of misoprostol was selected according to the gestational age. For women between 20 to 28 weeks, $100 \mu \mathrm{g}$ of misoprostol was used and for those beyond 28weeks, $50 \mu \mathrm{g}$ was used. If the first course of induction was unsuccessful, after a break of 12 hours, second course of induction was started with the vaginal misoprostol of same dose. In case of any adverse effects in either of the groups, further treatment was given as per discretion of concerned physician.

At the time of inclusion, data on maternal and gestational age, parity, previous deliveries, complications of pregnancy and status of the cervix were collected. Assessment of the cervix was based on Bishop scoring. ${ }^{9}$ Information on method of induction, dose of misoprostol, progression of labor, oxytocin use and mode of delivery were recorded. Length of hospitalization, maternal complications such as uterine rupture, blood transfusions, hysterectomy, endometritis, and admission to intensive care unit were analyzed. Additional collected data included the need for analgesia, evacuation of retained placenta and complications of delivery. Complete uterine evacuation was confirmed clinically by observing expelled products of conception: fetus and placenta. Clinical examination and ultrasonography was done in case of doubt regarding complete evacuation. Successful induction was defined as delivery within 24 hours of the first misoprostol dose.

The primary outcome was induction to delivery interval which reflects the time interval between first dose of misoprostol and expulsion of the fetus. Secondary 
Agrawal et al. Induction of Labor Using Misoprostol With or Without Mifepristone in Intrauterine Death

outcomes were number and total doses of misoprostol needed, need and duration of oxytocin use and complications like manual removal for retained placenta, uterine tachysystole, hyper tonicity, hemorrhage and coagulopathy. We also assessed adverse effects like nausea, vomiting, diarrhea and hyperthermia.

Data were analyzed using the SPSS version 17 for Windows Statistical Package. Comparison of numerical variables was done through independent sample t-test and Mann Whitney $U$ test as appropriate. Comparison of categorical variables was done using chi-square test and Fisher Exact test. Variables that were normally distributed are presented as means with standard deviations and ranges. Induction to delivery intervals were not normally distributed, hence non-parametric methods were used for comparison. Differences were regarded as statistically significant if $\mathrm{p}<0.05$.

A sample size analysis was performed before initiation of the study. Our hypothesis was that there would be reduction in induction-to-delivery interval after pre-treatment with mifepristone before induction with misoprostol. We considered approximate mean variation of sixty minutes to be clinically significant. On the basis of pre-existing data, it was calculated that it would be necessary to assign a total of 100 (50 per group) randomly to the two groups to detect a significant difference in the induction-to-delivery interval (employing confident interval at $95 \%$ level, power $80 \%$ ).

\section{RESULTS}

One hundred women were included in the study. At the end of study, we had complete data for all 100 women (50 in each group). All women in group A received 200 $\mathrm{mg}$ of oral mifepristone followed by induction with misoprostol after 24 hour. Eight women in this group did not receive misoprostol since seven of them had gone into labor without misoprostol and one woman developed antepartum hemorrhage so underwent hysterotomy. All women in group B were induced with misoprostol.

The groups did not differ significantly as regards to maternal age, gestational age, parity or cervical status (Table 1). Number of dosage of misoprostol needed in group $A$ was significantly less than group $B(p=0.04)$. Although different doses were used for women before and after 28 weeks of gestation, total dose of misoprostol used for women in both the group compared according to gestational age was not significantly different (Table 1).

\begin{tabular}{|c|c|c|c|}
\hline Variables & $\begin{array}{l}\text { Mifepristone } \\
\text { plus } \\
\text { Misoprostol }\end{array}$ & $\begin{array}{l}\text { Misoprostol } \\
\text { only }\end{array}$ & P-value \\
\hline $\begin{array}{l}\text { Mean (SD) } \\
\text { Age (years) }\end{array}$ & $27.4 \pm 5.9$ & $26.8 \pm 4.4$ & 0.543 \\
\hline $\begin{array}{l}\text { Gestational } \\
\text { age (weeks) }\end{array}$ & $31.5 \pm 6.5$ & $31.8 \pm 6.2$ & 0.765 \\
\hline \multirow{7}{*}{$\begin{array}{l}\text { Gravida } \\
\text { One } \\
\text { Two } \\
\text { Three } \\
\text { Four } \\
\text { Five } \\
\text { Six }\end{array}$} & & & \multirow{7}{*}{0.053} \\
\hline & $21(42.0 \%)$ & $19(38.0 \%)$ & \\
\hline & $10(20.0 \%)$ & $19(38.0 \%)$ & \\
\hline & $11(22.0 \%)$ & $12(24.0 \%)$ & \\
\hline & $03(6.0 \%)$ & $0(0 \%)$ & \\
\hline & $03(6.0 \%)$ & $0(0 \%)$ & \\
\hline & $02(4.0 \%)$ & $0(0 \%)$ & \\
\hline \multirow{6}{*}{$\begin{array}{l}\text { Parity } \\
\text { Zero } \\
\text { One } \\
\text { Two } \\
\text { Four } \\
\text { Five }\end{array}$} & & & \multirow{6}{*}{0.209} \\
\hline & $19(38.0 \%)$ & $23(46.0 \%)$ & \\
\hline & $17(34.0 \%)$ & $20(40.0 \%)$ & \\
\hline & 09 (18.0\%) & 07 (14.0\%) & \\
\hline & $03(6.0 \%)$ & $0(0.0 \%)$ & \\
\hline & 02 (4.0\%) & $0(0.0 \%)$ & \\
\hline \multirow{5}{*}{$\begin{array}{l}\text { Bishop } \\
\text { Score } \\
\text { One } \\
\text { Two } \\
\text { Three } \\
\text { Four }\end{array}$} & & & \multirow{5}{*}{0.177} \\
\hline & $15(30.0 \%)$ & $12(24.0 \%)$ & \\
\hline & $22(44.0 \%)$ & $20(40.0 \%)$ & \\
\hline & $09(18.0 \%)$ & $14(28.0 \%)$ & \\
\hline & $03(06.0 \%)$ & $0(0.0 \%)$ & \\
\hline
\end{tabular}

Using Mann Whitney $U$ test, median induction to onset of labor time was nine hours (range: 5-13.75) in group $A$, and 12 hours (range: $5-18.5)$ in group $B(p=0.03)$ (Table 2). Similarly the median induction to delivery time was 12 hours (9.6-22) and 17.5 hours (9-27.5) in group $A$ and $B$ respectively $(p=0.104)$. Also the total duration of labor in group $A$ was less than in group $B$ though it was not significant. In both the groups, duration of pregnancy did not have any effect on the induction to delivery time and total duration of labor (data not shown). Also the induction to delivery time did not differ between nulliparous and parous women in the two groups. 


\begin{tabular}{|c|c|c|c|}
\hline Variables & $\begin{array}{l}\text { Mifepristone plus misoprostol } \\
(n=42)^{*} \\
(\text { Mean } \pm \text { SD) }\end{array}$ & $\begin{array}{l}\text { Misoprostol only } \\
(n=50) \\
(\text { Mean } \pm \text { SD) }\end{array}$ & P-value \\
\hline Number of doses of misoprostol required & $3.00 \pm 1.309$ & $3.6 \pm 1.3$ & 0.04 \\
\hline $\begin{array}{l}\text { Total amount of misoprostol required } \\
\text { (mcg) }\end{array}$ & $200 \pm 18.5$ & $219 \pm 16.4$ & 0.43 \\
\hline Second cycle of misoprostol & $03(06.0 \%)$ & $06(12.0 \%)$ & 0.487 \\
\hline Misoprostol to labor interval (hours) & $9(5-13.75) \dagger$ & $12(5-18.5) \dagger$ & $0.03 \ddagger$ \\
\hline Misoprostol to delivery interval (hours) & $12(9.6-22) \dagger$ & $17.5(9-27.5) \dagger$ & $0.104 \ddagger$ \\
\hline Duration of labor (hours) & $3.5(2-5.8) \dagger$ & $4(2.4-8.5) \dagger$ & $0.450 \ddagger$ \\
\hline Requirement of oxytocin & $08(16.0 \%)$ & $11(22.0 \%)$ & 0.460 \\
\hline Duration of oxytocin (hours) & $6(3.16-7.2) \dagger$ & $3(2-3)+$ & $0.005 \ddagger$ \\
\hline Birth weight $(g)$ & $1000(500-2125) \dagger$ & $1500(600-2175) \dagger$ & $0.224 \ddagger$ \\
\hline Analgesic required & $4(8.0 \%)$ & $2(4.0 \%)$ & 0.48 \\
\hline
\end{tabular}

* In group 1 misoprostol was not required by 7 patients and one patient developed haemorrhage so, surgery had to be done $(n=42)$

$\dagger$ Median \pm Inter quartile range

$\ddagger$ Mann Whitney $U$ test used for comparison of numerical variables

In group A, $85.7 \%$ of women and $70 \%$ of women in group B delivered within 24 hours of first dose of misoprostol while rest of them delivered after 24 hours $(p=0.07)$ (Table 3$)$. Seven women in group A did not receive misoprostol as they had gone into labor and one woman had antepartum bleeding so was taken up for LSCS. Overall successful induction was achieved in $78 \%$ of women.

There were no significant difference in the need for second cycle of misoprostol for induction of labor after unsuccessful first cycle $(6 \%$ versus $12 \%)$ between the mifepristone-misoprostol and misoprostol only groups. Oxytocin was administered to $22 \%$ of women in misoprostol only group, the median duration being three hours (two-three hours) while the corresponding figures for the combined group were $16 \%$ and six hours (3.16-7.2) which was significant.

The duration of retention of dead fetus was not established as it cannot be ascertained accurately. There were no significant differences in the need for labor analgesia between the mifepristone-misoprostol and misoprostol only group ( $8 \%$ versus $4 \%$ ). Duration of hospital stay after delivery was 24 hour more in group $A$ and the birth weight (in grams) of the fetus (1000 [500-2125] versus 1500 [600 - 2175]) were similar in both the groups, respectively. No cases of uterine tachysystole, post-partum haemorrhage (PPH) or coagulopathy were recorded in any of the group.

\begin{tabular}{|c|c|c|c|}
\hline & $\begin{array}{l}\text { Delivery within } \\
24 \text { hours of } \\
\text { misoprostol }\end{array}$ & $\begin{array}{l}\text { Delivery } \\
\text { after } 24 \\
\text { hours of } \\
\text { misoprostol }\end{array}$ & P-value \\
\hline Group A & $36(85.7 \%)$ & $06(14.3 \%)$ & 0.07 \\
\hline Group B & $35(70.0 \%)$ & $15(30.0 \%)$ & \\
\hline
\end{tabular}

Note: In group 1, eight patients did not require misoprostol (seven patients had gone in labor before induction with misoprostol and one patient developed hemorrhage so, underwent hysterotomy).

\section{DISCUSSION}

The combination of mifepristone and misoprostol is well established in the management of early first trimester termination of pregnancy. ${ }^{3,4}$ Prior to availability of mifepristone, misoprostol only induction was used. But after it became widely available and used, it has also demonstrated significant effects on the uterus of late 
pregnancy. ${ }^{10}$ However, to our knowledge there are no randomized studies of combined treatment in cases of intrauterine death.

In our study, both combination of mifepristonemisoprostol and misoprostol only were effective and safe in induction of labor following IUFD. In both the groups combined, all the women except one had delivered vaginally with $78 \%$ of women delivering within 24 hours of enrolment. In women pre-treated with mifepristone, successful induction was $86 \%$. In study by Vayrynen $\mathrm{W}$ et al, ${ }^{11} 73 \%$ of women delivered within 24 hours using $25 \mu \mathrm{g}$ of misoprostol after pretreatment with mifepristone for women after 22 weeks of gestation. Study by Wagaarachchi et $\mathrm{al}^{6}{ }^{6}$ reported success rate of $98.9 \%$ but has described successful induction as delivery within 72 hours of induction. In their study delivery within 24 hour was $87.5 \%$. The dose of misoprostol used in their study was $200 \mu \mathrm{g}$ and $100 \mu \mathrm{g}$ for women before and after 34 weeks respectively. While in current study similar delivery rate was achieved with lower dose of misoprostol.

Pre-treatment with mifepristone decreased the number of dose of misoprostol required for women to go into labor. Vayrynen $\mathrm{W}$ et al, $^{11}$ showed larger number of misoprostol dose needed in the group pre-treated with mifepristone, compared to misoprostol only. This is in contrast to our results as higher dose of misoprostol was used in our study. In current study, women in group $A$ had gone into labor significantly earlier than women in group B (median nine hours versus 12h; $p=0.03$ ). Although data regarding induction to labor duration has not been given in other study, inductiondelivery interval after pre-treatment with mifepristone is lower in women induced with misoprostol.6,11 In our study, median induction to delivery interval was also lower in group A women. There was no significant difference in induction to delivery interval according to gestational age and parity in our study. Vayrynen $\mathrm{W}$ et al, ${ }^{11}$ showed that in the group treated with misoprostolonly, the dose needed was significantly lower when the duration of pregnancy was $\geq 31$ weeks. Thus it seems that mifepristone converts the pregnant uterus into a prostaglandin sensitive organ at all gestation.

Mifepristone increases uterine sensitivity to oxytocin when used for induction of term labor. ${ }^{12}$ However, in the present study, requirement for oxytocin was not significantly different (eight versus 11) in the group pre-treated with mifepristone and in the group receiving misoprostol-only. Among the women needing oxytocin, women in group A need it for significantly longer duration. However, the potentially different need of oxytocin might be because of small number of women requiring oxytocin.

In current study, no complication was reported in either of the group and need for labor analgesia were similar in both the groups which was similar to the result of Vayrynen $W$ et al. ${ }^{11}$ Although fever and the use of antibiotics were more common in group pre-treated with mifepristone in their study, current study did not show such effects. We did not attempt to determine the causes of fetal death in our study because of lack of facility for post-mortem examination of the fetus.

Although with mifepristone-misoprostol, the resultant delay in commencing IOL by 24 hours is a disadvantage, combination regimen is preferable. Administration of the oral dose of mifepristone at home may be feasible and it will also reduce the hospital cost of one day. But this protocol needs to be evaluated in randomized study. However because of increase cost of mifepristone, in setting where costs are prohibitive, regimens with only misoprostol may be appropriate.

\section{CONCLUSIONS}

In induction of labor following IUFD, after 20 weeks gestation, both the regimen of mifepristone-misoprostol and misoprostol only were less invasive, effective and safe. However the combined use of mifepristone and misoprostol results in less number of misoprostol dose needed for induction of labor and thus early onset of labor without any increase in adverse effect.

\section{ACKNOWLEDGEMENTS}

We would like to thank Dr Reshu Agrawal Sagtani (BDS, $\mathrm{MPH})$ who performed quality assurance checks on data and helped in study analysis.

\section{REFERENCES}

1. Kochenour NK. Management of fetal demise. Clin Obstet Gynecol. 1987 Jun;30(2):322-30.
2. Ngai SW, Tang OS, Ho PC. Prostaglandins for induction of second-trimester termination and intrauterine death. Best Pract Res Clin Obstet Gynaecol. 2003 Oct;17(5):765-75. 
3. Ashok PW, Flett GM, Templeton A. Effective, low-cost regimens for medical termination of pregnancy at all gestations. Contemp Rev Obstet Gynaecol. 1999;11:207-12.

4. Ashok PW, Penney GC, Flett GM, Templeton A. An effective regimen for early medical abortion: a report of 2000 consecutive cases. Hum Reprod. 1998 Oct;13(1O):2962-5.

5. Jannet D, Aflak N, Abankwa A, Carbonne B, Marpeau L, Milliez J. Termination of 2nd and 3rd trimester pregnancies with mifepristone and misoprostol. Eur J Obstet Gynecol Reprod Biol. 1996 Dec 27;70(2):159-63.

6. Wagaarachchi PT, Ashok PW, Narvekar NN, Smith NC, Templeton A. Medical management of late intrauterine death using a combination of mifepristone and misoprostol. BJOG. 2002 Apr;109(4):443-7.

7. Fairley TE, Mackenzie M, Owen P, Mackenzie F. Management of late intrauterine death using a combination of mifepristone and misoprostol--experience of two regimens. Eur J Obstet Gynecol Reprod Biol. 2005 Jan 10;118(1):28-31.
8. Royal College of Obstetricians and Gynaecologists (RCOG). Late intrauterine fetal death and stillbirth. London (UK): Royal College of Obstetricians and Gynaecologists (RCOG); 2010 Oct. 33 p. (Green-top guideline; no. 55).

9. Bishop EH. Pelvic scoring for elective induction. Obstet Gynecol. 1964 Aug;24:266-8.

10. Stenlund PM, Ekman G, Aedo AR, Bygdeman M. Induction of labour with mifepristone: a randomised, double blind study versus placebo. Acta Obstet Gynecol Scand. 1999;9:793-8.

11. Vayrynen W, Heikinheimo O, Nuutila M. Misoprostol-only versus mifepristone plus misoprostol in induction of labor following intrauterine fetal death. Acta Obstetricia et Gynecologica Scandinavica. 2007; 86:701-5.

12. Giacalone PL, Daurés JP, Faure JM, Boulot P, Hedon B, Laffargue $F$. The effects of mifepristone on uterine sensitivity to oxytocin and on fetal heart rate patterns. Eur J Obstet Gynecol Reprod Biol. 2001 Jul;97(1):30-4. 